\title{
ANTIGEN UPTAKE IN ZEBRAFISH (DANIO RERIO) AT DIFFERENT LIFE STAGES
}

\author{
Rozalia Korbut, Foojan Mehrdana, Per W. Kania, Marianne H. Larsen, Dorte \\ Frees and Louise v. G. Jørgensen* \\ Faculty of Health and Medical Sciences, University of Copenhagen, Frederiksberg, \\ Denmark
}

Immersion-vaccines (bacterins) are routinely used for aquacultured rainbow trout to protect against Yersinia ruckeri (Yr). They consist of formalin killed bacteria and during immersion, lasting at least 30 seconds, rainbow trout take up and process the antigens, which induce protection. However, uptake mechanisms and processing are still insufficiently elucidated. We have used zebrafish as a model organism to study uptake mechanisms and subsequent antigen transport in fish. A genetically modified Yr was developed to constitutively express GFP (green fluorescent protein) and subsequently used for bacterin production. Larval, juvenile and adult transparent zebrafish (tra:nac mutant) were immersed in the bacterin for up to 30 minutes. Samples were taken after $1 \mathrm{~min}, 15 \mathrm{~min}, 30 \mathrm{~min}, 2 \mathrm{~h}, 12 \mathrm{~h}$ and $24 \mathrm{~h}$. At each sampling point two fish were used for live imaging using a fluorescence stereomicroscope and three fish were also sampled for immunohistochemistry (IHC). Bacteria could be traced in scale pockets, skin, esophagus, intestine and fins of adult fish. However, within two hours post-immersion Yr-antigens were visible in the spleen and within $24 \mathrm{~h}$ in liver and kidney. Bacteria were associated with the gills but uptake at this location was limited. Antigens were not seen in the nares and rarely in the blood. In juvenile fish the nares and intestine were major uptake sites, whereas scale pockets did not stain positive. Antigens were detectable in the spleen $12 \mathrm{~h}$ post immersion. Zebrafish larvae exhibited Yr uptake in mid-intestine enterocytes $24 \mathrm{~h}$ following immersion. The different zebra fish life stages varied with regard to uptake locations, but the gut was consistently a major uptake site in all stages. Zebrafish and rainbow trout tend to have similar uptake mechanisms following immersion vaccination, which may suggest zebrafish as a suitable model organism for this aquacultured species.

Keywords

Zebrafish, rainbow trout, immersion vaccine, antigen uptake, Yersinia ruckeri.

§Louise v. G. Jørgensen

Tel.: +45 22833464

E-mail address: lvgj@sund.ku.dk 